\title{
Fuzzy Controllers: A Reliable Component of Smart Sustainable Structural Systems
}

\author{
Maguid H. M. Hassan
}

Additional information is available at the end of the chapter

http://dx.doi.org/10.5772/48263

\section{Introduction}

Structural control has been introduced, several decades ago, as one of the basic forms of smart systems [1,2]. The structural system's performance is enhanced by the presence of a closed loop feedback controller that employs observed data, about the system's responses, in evaluating and applying corrective actions in order to improve its performance. Initially, conventional control theory has been the backbone of such controllers [1, 2]. Yet, the sheer complexity and size of such structural systems, coupled with the time required for solving the control problem and thus evaluating the necessary corrective actions, limited the applications of such concepts. Needless to say, such systems are intended to operate real time during the occurrence of earthquake events, which are usually over in about few minutes at the most. Recently, smart control algorithms have been introduced in an attempt to fill that gap $[3,4]$.

Fuzzy control is one of the smart control strategies that were employed in structural control recently $[5,6]$. Fuzzy controllers employ a set of input control variables, a rule-base and an inference engine to infer proposed actions aiming at the improvement of the system's performance [7]. Several factors are crucial to a successful fuzzy controller design, namely, membership functions of fuzzy variables, rule-base generation and suitable implication functions [7]. Several membership functions were employed in various applications of fuzzy controllers. It is imperative to select the membership functions that best captures the nature of the modeled variables [7]. The generation of a relevant and suitable rule-base is another major concern, several approaches have been employed, such as relying on expertise of human operators as opposed to designing a smart algorithm which would generate the rule-base, such as neural networks. Finally, appropriate implication functions should be carefully selected in order to reflect the proper and expected performance of the designed controller. 
Fuzzy control, as a heuristic-based control strategy and given the uncertain nature of the problem in question, would definitely require a reliability assessment and assurance algorithms to reinforce its implementation in such a critical application. Successful reliability evaluation of any given system is performed in consecutive steps that start with creating a comprehensive reliability assessment framework, developing a system model, complete definition of potential failure modes, transformation of such failure modes into limit state equations and finally the calculation of the reliability measures for the component and/or system in question.

In this chapter, the design of fuzzy controllers, tailored for functioning as structural controllers, is outlined together with all necessary definitions of relevant variables, their membership functions, fuzzification and de-fuzzification procedures. The definition of the required inference engine and its underlying rule-base, implication functions and inference mechanisms are also presented. Knowing the importance of reliable performance of such heuristic systems and to ensure their general applicability, a reliability assessment procedure is also outlined to evaluate the reliability of the designed controllers. Finally, other potential applications of fuzzy inference systems are also briefly presented, such applications include, but not limited to, smart abstract deformed shape identification of structural systems under earthquake excitation.

\section{Smart sustainable structural systems}

\subsection{Introduction}

Sustainable design entails a range of actions, decisions and procedures that would result in an environmentally friendly structural system. Such a concept has long been ignored in structural engineering and when realized was taken as one that relates to a single dimensional approach which always referred to the use of recyclable materials. Surely, recyclable materials are considered one of the main players in such a design problem, however, structurally speaking this process requires a multi faceted approach that employs higher levels of design decisions and considerations. A sustainable structural system would be one that employs the optimum amount of environmentally friendly construction materials with ensured reliable performance along its expected life time. The keywords here are being recyclable, optimum and reliable. Therefore, when designing a structural system that is expected to withstand uncertain loading conditions, such as earthquake loads, it is more sustainable to design a smart system that is capable of adjusting its own physical and/or engineering characteristics in order to improve its response to such loads, as opposed to a system that is designed to resist loads that it may or may not encounter during its life time. Smart systems, by definition, would result in lighter more optimum systems which definitely would be even more sustainable if they are constructed using a recyclable material, such as structural steel. Even if more invasive materials were used, such as, reinforced concrete, the optimum design coupled with the smart features would result in a more sustainable system. Therefore, it is proposed that if it is possible to design reliable smart structural systems, this would result in a more sustainable structural design. 
Smart structural systems are defined as ones that demonstrate the ability to modify their characteristics and/or properties in order to respond favorably to unexpected severe loading conditions [8]. Conventional structural systems are usually designed to resist predefined loading conditions. However, due to the uncertain nature of engineering systems, and the lack of complete and accurate information about some types of highly uncertain loads, such as earthquakes, smart structural systems have emerged as a potential solution for such problems. Instead of designing systems to withstand a single extreme earthquake event that may or may not occur in its lifetime, new designs of smart systems could emerge where the system is capable of responding favorably, in a smart manner, to any type of loading that was not specifically considered at the design stage. The significance of such systems is even further enhanced when modeled systems are unconventional such as historic buildings and/or structures.

As in all engineering endeavors, with a long deep look at god's creations, one can surely develop a lot of smart ideas. For example, if a similarity is drawn between a human trying to balance himself on a shaky table, and a building trying to balance itself on a shaking ground. The first, develops no mathematical models, solves no complicated sets of equations and yet is successfully capable of balancing himself. He simply employs three basic properties of his. First, his sensing capabilities, through his nervous system, which sends messages to his brain, signaling that an adverse effect is about to happen. The brain uses this piece of information and, based on its collection of experiences and reasoning capabilities, develop a balancing solution for the problem. The brain, then, sends specific commands to a set of muscles that are capable of restoring the balance of the human body. The body is balanced throughout a smart procedure that started with data collection about the current state of the body, then, data processing, state identification and problem solving. The final step is action implementation.

If a building is required to balance itself on a shaking ground, in a similar manner, it should employ similar smart procedures. Therefore, for any structural system to behave in a smart manner, it should go through three basic steps. First, it has to realize, somehow, what is going on in terms of adverse effects. Second, it should be able to process this information, i.e., translate that into state identification, and accordingly decide the type of necessary countermeasures. Third, it should have the ability to perform whatever corrective action is required. A structural system, designed as such, should employ three basic components, integrated within its structure, in order to be able to perform the previously mentioned activities.

- First, Sensors, which are analogous to the human nervous system, shall be employed in order to measure and register important internal and external information and / or changes.

- $\quad$ Second, Processors, which are brain-like units, that are responsible for interpreting the collected data into meaningful state identifications and accordingly necessary corrective actions to be taken.

- Third, Actuators, which are elements that maintain the capability of adjusting either the system structural characteristics or its own characteristics in order to respond favorably to external excitation. 
According to the type and nature of the employed components, several levels of smart systems could be developed. It should be realized that both the actuators and processors, in a human being, have additional levels of smartness based on their nature. For example, the muscles, i.e., the actuators, exert a variable amount of force depending on the signals sent by the brain. The brain, itself, employs highly adaptive thinking and learning techniques in its reasoning process. Therefore, multiple integrated levels of smart structural systems could be realized according to the type and properties of the components used in its development. As the level of integration increases, the level of smartness of the resulting system increases. Figure 1 shows a model of a smart single-degree-of-freedom system, while Figure 2, shows a smart three-story building. Both figures outline the inter-relations among the additional components that drive the performance of the smart system. It should be noted that multidegree-of-freedom systems require a more complex processor that incorporates two main components, i.e., a fuzzy state identifier in addition to the fuzzy controller. The state identifier is required to define the deformed shape of the system, thus, guiding the firing sequence of relevant actuators. The following discussion outlines the properties of each of the three basic components in the sake of providing a comprehensive description of the system under consideration.

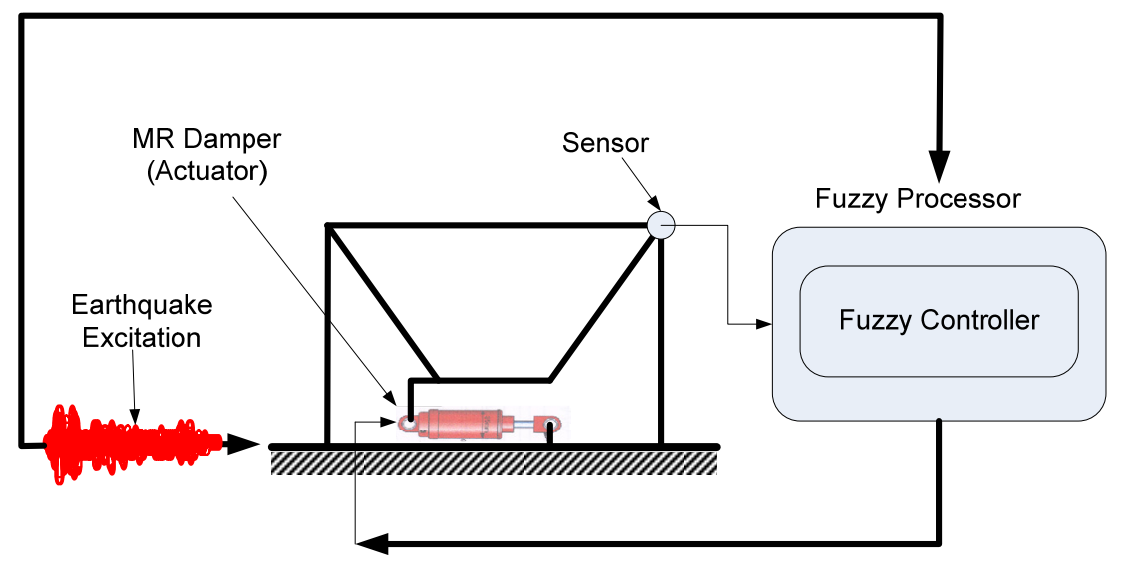

Figure 1. Smart Single-Degree-of-Freedom System

\subsection{Sensors}

Sensors are the first component of any smart structural system. The system needs to be able to identify any changes occurring to its state in order to perform any corrective action [8]. The monitoring operation could be implemented in two possible modes. The first mode is a continuous monitoring for a select group of parameters, such as displacements, velocities and accelerations. The second mode is a continuous monitoring for a select group of damage indicators such as cracking, fatigue, corrosion or excessive deflections. The smart structural system application, in question, dictates the required mode of monitoring. Currently, such systems are either designed for structural control, or for structural health monitoring 
applications. The first application requires the first mode of monitoring, while the second application requires the second mode of monitoring.

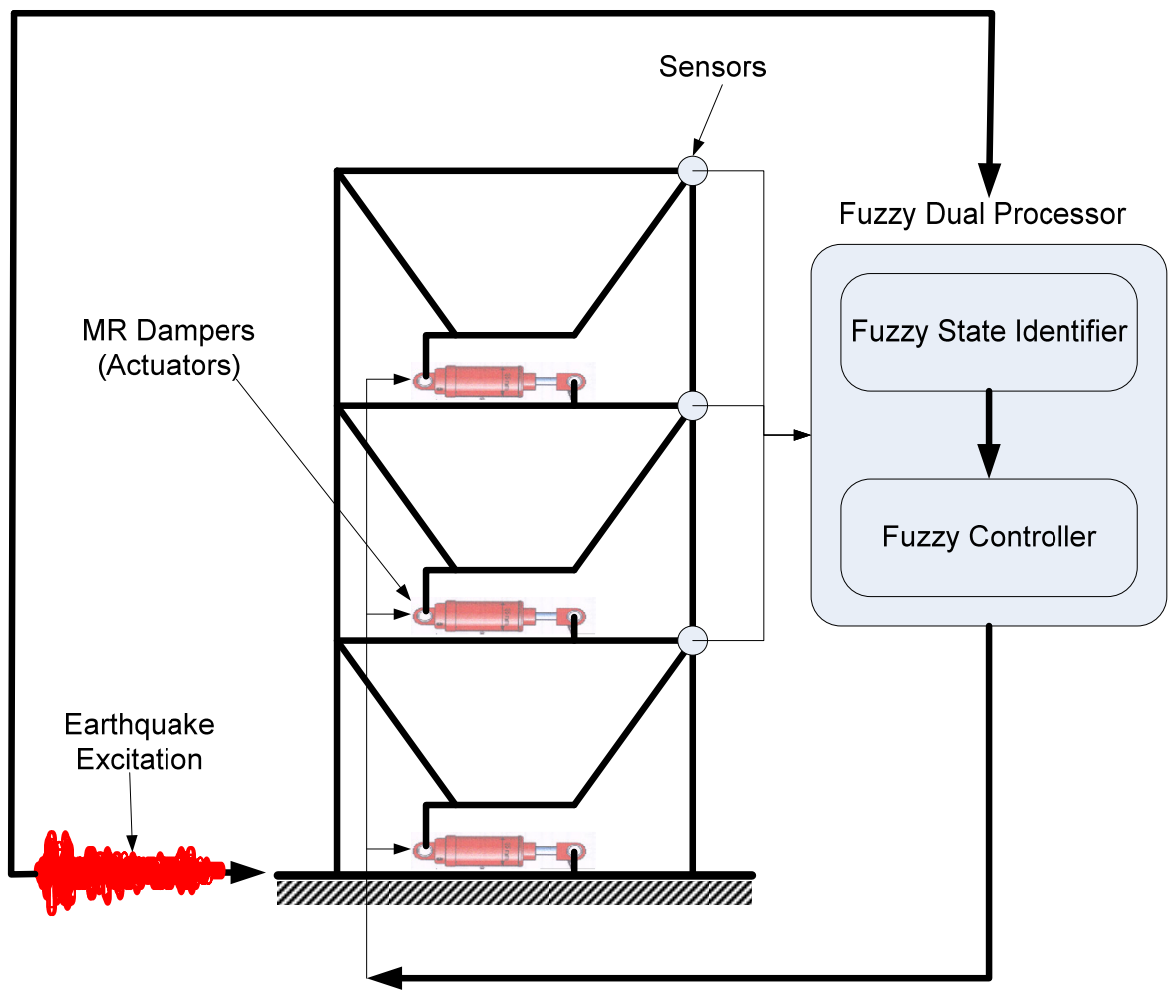

Figure 2. Smart Sustainable Steel Frame

There are several potential sensor technologies that are being used or considered for the smart structural applications in civil engineering. As indicated earlier, a higher level of smartness is attained if smart materials are used as sensors in addition to, or instead of, conventional sensor technologies. Conventional sensor systems are ones that do not posses any smart potential. In other words, such materials are incapable of altering or adjusting their own characteristics in response to external excitation. Their role would be to measure specific state variables and send such records to the processor unit for state identification and corrective action evaluation. Such sensors are very well documented and have been implemented in civil / structural applications for a long time. As an example, Displacement Transducers, Velocity and Acceleration Transducers and Strain Transducers are considered as conventional sensors. Smart sensors, on the other hand, by definition are ones that are capable of altering or adjusting their characteristics in response to external excitation. Such excitation might be temperature, electric current or mechanical movements, piezoelectric ceramics and optical fibers are examples of such smart sensors. 


\subsection{Processors}

Processors are brain-like units that are capable of evaluating the current state of the system, based on the data communicated by the sensors, and proposing corrective actions accordingly [8]. The processor shall be capable of operation in one of two modes. The first mode is system monitoring, where the processor only identifies the state of the system without taking any remedial actions. The second mode is system control, where the processor is called upon to identify the state of the system, evaluate the proper corrective action to be taken and implement the suggested action automatically. It should be pointed out that system control mode, by definition, employs system monitoring mode as a subsequent major component. One of the major factors that would dictate the mode of operation of the processor is the type of application and the state parameter being monitored. For example, RC elements might be supplied with a monitoring system, in order to identify any potential damage to a given element, such as steel corrosion, concrete cracking, excessive deflection, etc. The processor, in this case, is only called upon to identify the occurrence of a certain type of damage. Furthermore, any structural system could be supplied with a control system that is capable of suppressing the vibration and balancing the system under wind and earthquake excitations. Thus, a processor operating at the control mode would be required for such an application.

\subsection{Actuators}

Actuators act as the muscles of the structural system. Actuator technology is responsible for the development of materials and/or devices that would either apply control forces to the system or add new characteristics to the structure [8]. Actuators do not necessarily apply balancing forces to the structural system. In case smart actuators are utilized, the system adjusts its structural characteristics without any introduction of external forces, which is the current preferred approach.

All applications that employed conventional actuator technologies were in the field of structural control [1,2]. Structural control is one of the early applications of smart structural systems. There are three potential schemes of structural control, namely, Passive, Active and Semi-Active [1, 2, 4]. Passive control employs energy dissipation components that are designed for predefined limits and possess no adaptive capabilities. Although most of the practical applications of structural control, currently in operation, are of this primitive type, they do not show efficient performance under real conditions. Active Control employs the basic conventional structure of a smart structural system. It comprises sensors, processors and actuators that are, predominantly, of the conventional type [1,2]. This type of control exerts an external control force that is utilized in balancing the system in response to external loads. Semi-Active control has received increased attention recently as the most practical and state of the art control system [3,4]. Semi-Active control employs actuators that are, predominantly, of the smart type. Such actuators cannot inject mechanical energy directly to the system, yet, they have the ability to adjust their properties in a way to optimally adjust the response of the system under unforeseen external events. Some of the 
smart actuators which are currently being explored for application in civil engineering systems are Shape Memory Alloys (SMA), Piezoelectric Ceramics, Electro-Rheological (ER) fluids, and Magneto-Rheological (MR) fluids. MR fluids, which are employed in manufacturing MR dampers, have already reached full-scale applications and showing very promising results in civil engineering applications $[3,4]$.

\section{Fuzzy controllers as processors}

Fuzzy controllers are known to employ fuzzy logic and fuzzy set theory in developing their control strategies and evaluating control actions [9, 10, 11, 12, 13]. Fuzzy logic has two primary advantages, as opposed to conventional mathematical algorithms, when employed in control applications. First, it reduces the difficulties of modeling and analysis of extremely complex systems. Second, it is capable of incorporating several qualitative aspects of the human knowledge in the control laws [10, 11, 12, 13]. Fuzzy control is based on the fuzzy set theory which allows for the qualitative, imprecise and/or vague information to be quantitatively included in the evaluation of a representative control action $[5,6,7,10,11,12,13]$. Such inherent uncertainty would probably be ignored in a conventional mathematical algorithm, thus, rendering inaccurate control forces. Fuzzy set theory utilizes a very important tool in its manipulation procedure, which is the membership function [7]. The membership function, usually takes one of the following forms, i.e., triangular, trapezoidal or Gaussian, in order to evaluate a degree of membership for the element in question. This degree of membership is the major difference between this approach and conventional mathematical methods. Fuzzy control comprises four main components $[5,6,7,10,11,12,13]$;

- Fuzzification: the state variables to be monitored, when measured, have crisp values. These values should be fuzzified, using fuzzy linguistic terms defined by the membership functions of the individual fuzzy sets.

- Rule-Base: is a collection of If-Then rules describing the control laws governing the evaluation of necessary control actions.

- Inference Engine: comprises two main stages, namely, Implication and Aggregation. The implication procedure evaluates a control action from each applicable rule, given a certain input fuzzy value. The Aggregation procedure evaluates a collective control action, i.e., output, by adding all control actions from all applicable rules in a predefined manner.

- Defuzzification: the resulting control action is in a fuzzified form that could not be applied to any actuator device. Thus, this step evaluates an equivalent crisp value for the fuzzy collective control action.

The processor, as identified in smart structural applications could perform two main tasks, the first is state identification, if necessary, while the second is control action evaluation. Figure 1 shows a fuzzy controller without a state identifier, while Figure 2 shows a fuzzy dual processor which comprises a fuzzy state identifier and a fuzzy controller. The fuzzy controller would employ the input variables in addition to the output of the fuzzy state 
identifier in evaluating the appropriate control action. The following sections outline the implementation of fuzzy control in the development of the controller component of the processor while the fuzzy state identifier is discussed in section 5. The reliability of fuzzy controllers when operating within the smart system is a major concern if such a setup is considered for designing systems that are sustainable as defined above. The reliability framework and assessment procedures for fuzzy processors are discussed in section 4 of this chapter.

\subsection{Input variables}

Fuzzy controllers usually employ two input variables one is an error measure while the second is a rate of change of that error [7]. In that context, it is usually required of the controller to monitor the performance of the modeled system in order to minimize or even eliminate the error if possible. In case of structural control, this corresponds to the dynamic movement of the controlled system which is generally measured by the velocity of a select set of control points referred to as degrees of freedom [8]. Such degrees of freedom correspond to the floor levels of the framed building shown in Figures 1 \& 2 and have assigned sensors to measure their movements. The rate of change of the measured variable, i.e., velocity, would be the acceleration of the control points. Therefore, in structural control applications it is expected to include the velocity and the acceleration of degrees of freedom as input variables to the fuzzy controllers. When dealing with complex systems, having so many degrees of freedom, and in order to attain the objective of reliable, optimum and sustainable systems, it is expected that the control actions would not be required of all actuators, however, a select group of actuators which are identified based on the deformed shape of the controlled building would be fired. Therefore, the input variables to the fuzzy controller should include an additional input variable which classify the current deformed shape of the monitored building. Thus, three dimensional rules would be necessary to drive the inference engine of structural fuzzy controllers. Input variables, as well as, output variables need to be fully defined as part of the design of a fuzzy controller. Such definition would not be complete without the identification of a suitable membership function for each variable.

\subsubsection{Membership functions}

A major step in defining control variables in fuzzy control applications is the definition of membership functions [7]. Such a task has to be performed in two main underlying steps. The first is the selection of the range of values which the function should cover while the second is the type of membership function to be employed and its relevant parameters. Several membership functions were reported successfully in several fuzzy control applications, such as, triangular, trapezoidal and Gaussian functions [7]. For structural control applications it is expected that either triangular and/or Gaussian membership functions would be suitable for modeling control input and output variables. The proper identification of a representative range of values for properly defining such membership functions should be based on actual 
results of the modeled system. In order to evaluate the range of values, a structural model of the system under consideration should be created and a time history analysis shall be conducted $[14,15,16]$. The results of such an analysis would generate all potential values of velocities and accelerations of control points. These values could be used in identifying several bands within the expected range, correlate these bands to fuzzy variables and evaluate the required parameters, for each band, of the velocity and/or acceleration [17].

Gaussian Membership Functions, The Gaussian membership function is fully defined by two main parameters, namely, the average value and the standard deviation. Figure 3 outlines a generic Gaussian membership function with the expected form of the function [7, 8]. When modeling input and/or output variables using a Gaussian membership function, the time history of the modeled variable needs to be evaluated using a finite element model of the structural system under consideration. The resulting time history would allow the segmentation of the variable range into several bands with relevant fuzzy labels and suitable standard deviations.

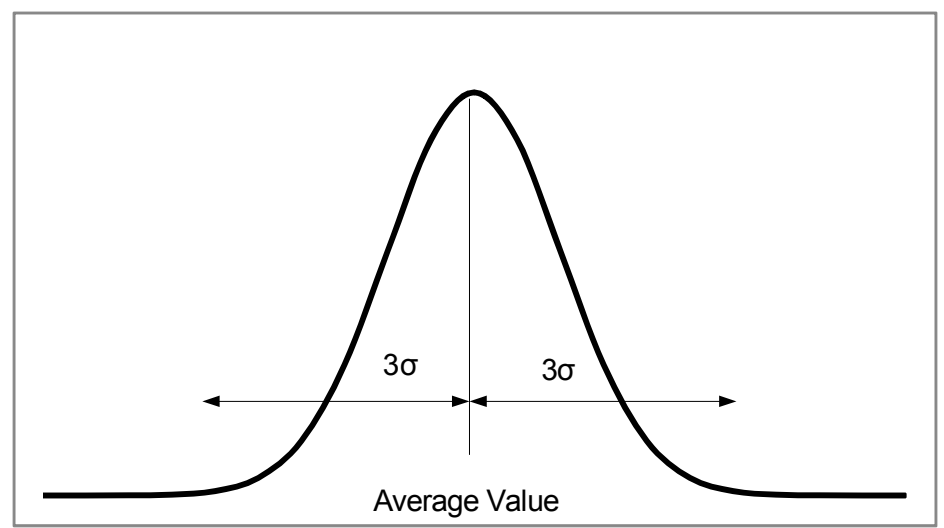

Figure 3. Generic Gaussian Membership Function

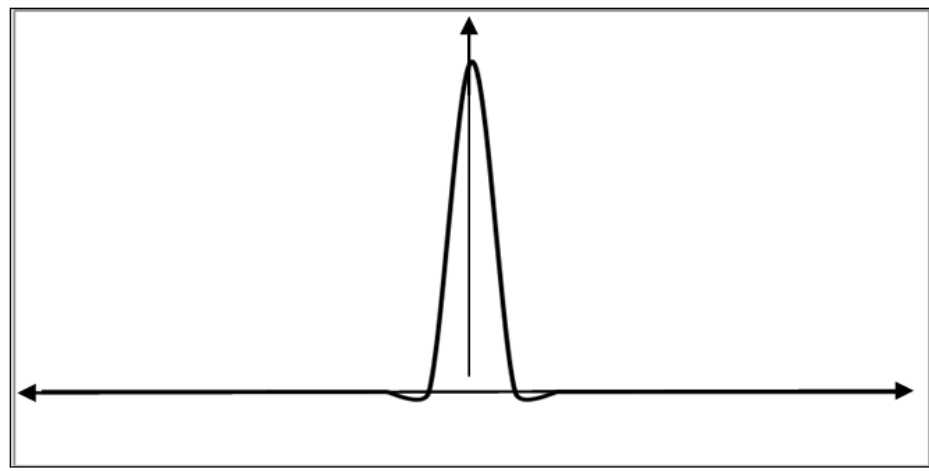

Figure 4. A Singleton Gaussian Fuzzy Variable with Zero Label 
For example a fuzzy variable with a zero label would have a zero average value and a very narrow standard deviation to simulate the singleton value of zero as shown in Figure 4. While a negative fuzzy variable would have a negative average value, that is equivalent to the range of values the variable takes as indicated by the time history analysis results, and a suitable standard deviation to model the dispersion about this average value as shown in Figure 5.

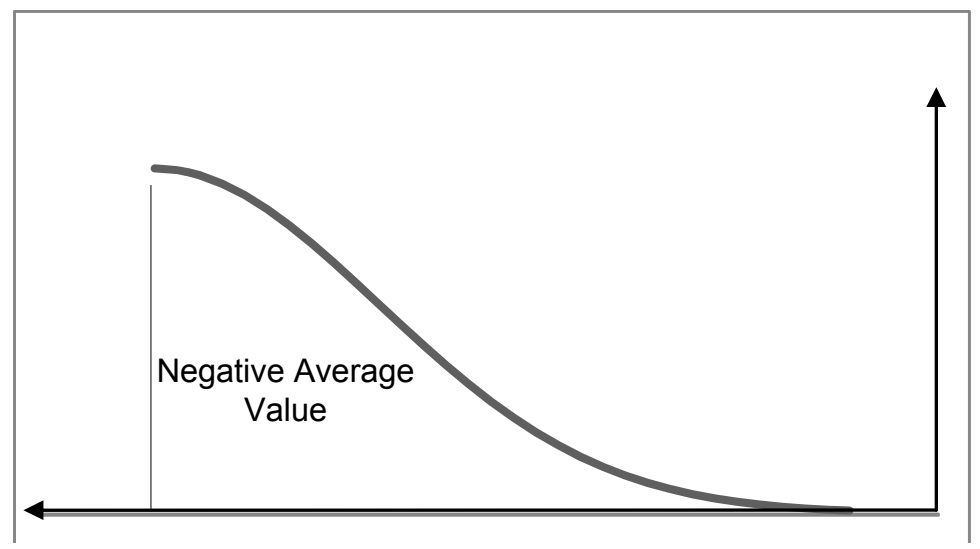

Figure 5. A Gaussian Fuzzy Variable with Negative Label

The standard deviation in the first case was selected to be 0.001 to reflect the narrow range and refelect the singleton nature of the zero label, while the standard deviation in Figure 5 was selected to be 1 to reflect the uncertainty associated with the negative label. Depending on the range of input variables some or all of the memebrship functins could be used in modeling the variable.

Triangular Membership Functions, The triangular membership function is one of the most widely used and successful membership functions in a wide variety of applications [7, 11, 12, 17]. Figure 6 shows a generic triangular membership function where three basic parameters are necessary in order to fully define the function [17]. The parameters are identified as ( $a, b$ and c) in Figure 6 where (a) represents the lower bound of the function, (b) defines the average value and (c) defines the upper bound of the membership function. As in the case of Gaussian membership functions, the range of input values would dictate if the whole function is employed or just a portion is only enough to represent the modeled variable. Moreover, the amount of uncertainty incorporated in the function which is measured by the triangular base of the function, i.e., (c-a), is also problem dependant and should be evaluated based on the actual data resulting from the finite element model of the system. If the same variables, modeled with Gaussian membership functions, are modeled using triangular functions, the zero fuzzy label and the negative fuzzy label would be defined as shown in Figure 7 


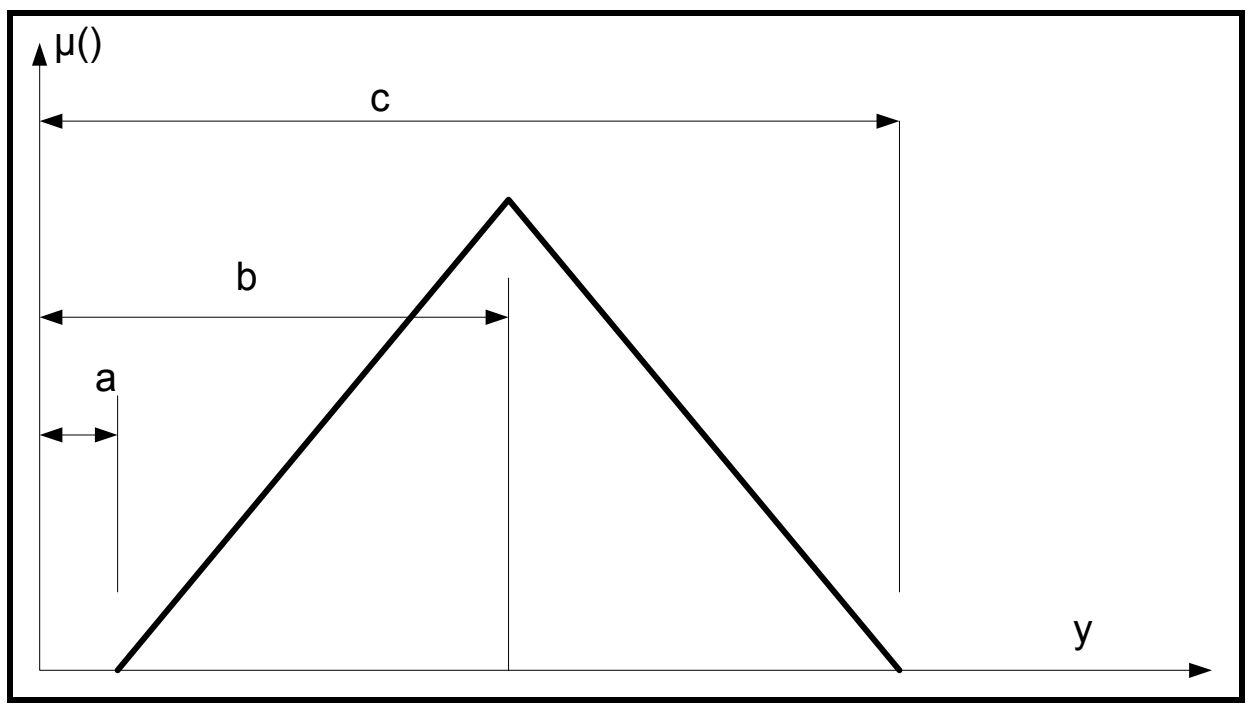

Figure 6. Generic Triangular Membership Function

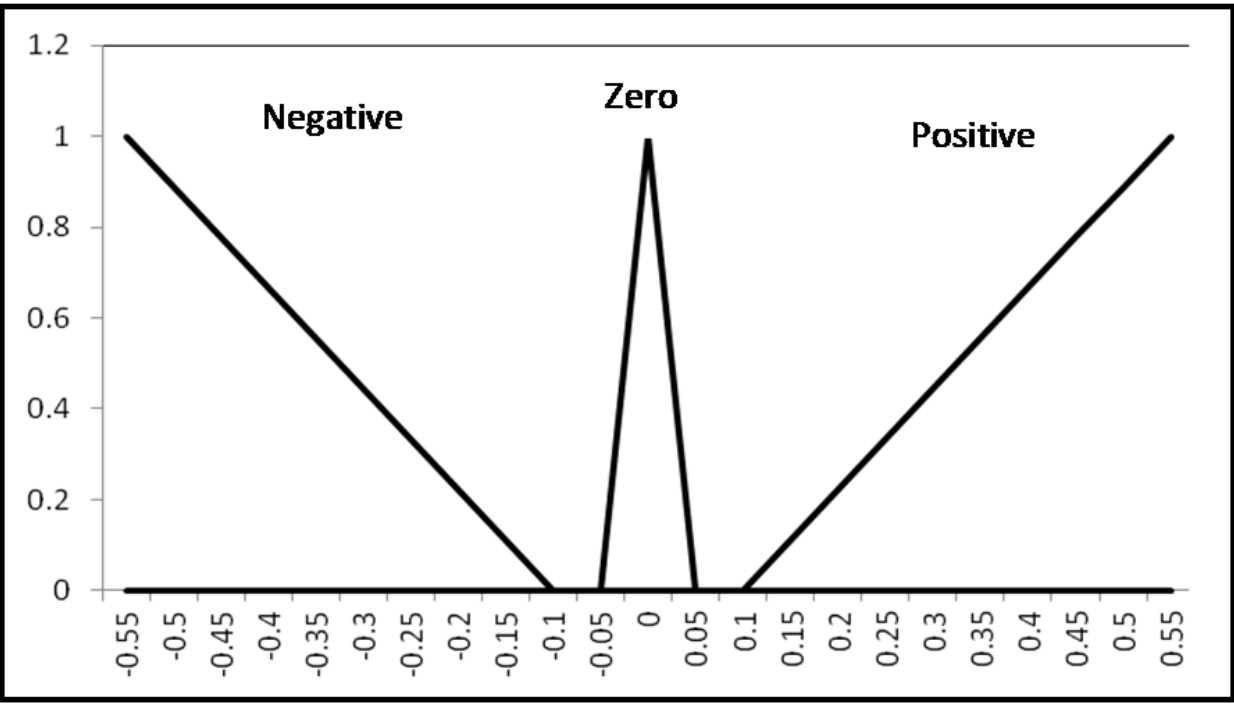

Figure 7. Triangular Fuzzy Variable with Zero, Positive \& Negative Labels

The triangular membership functions for variables shown in Figure 7 are defined mathematically as follows:

$$
\mu_{\text {NEGATIVE }}(x)=\left\{\begin{array}{c}
\frac{x}{L B} \text { for } L B \leq x \leq 0 \\
0 \text { for all other values of } x
\end{array}\right.
$$




$$
\begin{gathered}
\mu_{\text {ZERO }}(x)=\left\{\begin{array}{r}
-\frac{1}{10^{-6}}\left(-10^{-6}-x\right) \text { for }-10^{-6} \leq x<0 \\
\frac{1}{10^{-6}}\left(10^{-6}-x\right) \text { for } 0 \leq x<10^{-6} \\
0 \text { for all other values of } x
\end{array}\right. \\
\mu_{\text {POSITIVE }}(x)=\left\{\begin{array}{c}
\frac{x}{U B} \text { for } 0 \leq x \leq U B \\
0 \text { for all other values of } x
\end{array}\right.
\end{gathered}
$$

Where, $\mu_{\text {NEGATIVE }}(),. \mu_{\text {ZERO }}(). \& \mu_{\text {POSITIVE }}()=$. are the membership functions for the three fuzzy states of an input variable, NEGATIVE, ZERO \& POSITIVE respectively; LB \& UB = are the lower and upper bounds of the interval holding the range of values of the variable, as evaluated by a time history analysis, at any point in time, $\mathrm{LB}<0$ and $\mathrm{UB}>0$; and $\mathrm{x}=$ is the value of the variable, at any point in time. For the shown membership functions in Figure 7 the bounds of the interval holding the variable range of values is $[-0.55,0.55]$.

\subsection{Inference engine}

Fuzzy controllers are built on top of an inference engine which employs a rule-base that summarizes the necessary knowledge for inferring actions and an inference engine which performs the evaluation process based on fuzzy logic [7, 12]. The Inference engine comprises inference functions, inference mechanisms and aggregation functions that would combine the results of relevant fired rules into a single fuzzy output variable. There are several types of inference mechanisms, however, the most widely used in control applications is Mamdani's inference [7, 12]. The nature of the problem at hand and its impact on the evaluation of the overall output variable dictates the choice of the relevant inference mechanism [7, 12]. The details of the inference mechanism are beyond the scope of this chapter, however, the method of developing a representative rule-base is further discussed in this section with examples from structural control applications.

It is first important to identify the structure of the rule before building a rule-base. Rules could be multi-dimensional depending on the nature of the problem. In other words, rules could construct a one-to-one mapping between a single input and a single output, or a many-to-one mapping where several input variables are mapped to a single output variable. The number of inputs necessary to infer an output is obviously a problem dependant factor. In structural control applications it is necessary to include at least two measurable input variables in order to infer realistic output values [12]. Usually these two variables are some measure of error and rate of change of that error. The interpretation of an error term would be different from one application to the next. In case of structural control problems, any variable that would measure the movement of the system as a result of dynamic load effects, e.g., earthquakes, would qualify as an error measure. Therefore, it is reasonable to employ 
the velocity of predefined degrees of freedom as the error measure while the acceleration, which is the rate of change of the velocity, would be employed as the second input variable [12]. Therefore, structural control applications should at least involve two input variables in their rules. This setup would be enough for s single degree-of-freedom system, as shown in Figure 1, where the movement of a single floor would completely define the deformed shape of the system and thus the necessary action to restore the original shape of the system. In case of multi-degree-of-freedom systems, such as the system shown in Figure 2, a third input variable is necessary in order to provide additional information about the abstract deformed shape of the structural system. The need for that additional variable is reflected in the enhanced fuzzy processor where a fuzzy pattern identifier is integrated with the controller in order to identify the abstract deformed shape of the system [19]. This information is crucial in firing relevant actuators with the proper output value and sequence. Therefore, rules that would drive the operation of a smart sustainable multidegree-of-freedom structural system are expected to employ three input variables and a single output variable [19].

In reference to a single degree of freedom system, as shown in Figure 1, a sample rule should include two input variables and a single output variable. The input variables are the velocity and acceleration of the floor level, while the output variable is the voltage which is communicated to an MR damper in order to restore the system's un-deformed shape. The rule could be defined as follows:

$$
\text { IF } \dot{D}(t) \text { is BIG AND } \ddot{D}(t) \text { is NEGATIVE SMALL THEN } V(t) \text { is SMALL }
$$

Where, $\dot{D}(t)=$ is the velocity at the floor level at a given point in time $(\mathrm{t}), \ddot{D}(t)=$ is the acceleration at the floor level at a given point in time $(t), V(t)=$ is the command voltage at a given point in time $(t)$, and BIG, NEGATIVE SMALL and SMALL are fuzzy variables. On the other hand, in reference to the smart system defined in Figure 2, the fuzzy controller would accept the velocity and acceleration of a given degree of freedom in addition to an abstract deformed pattern, as input and produce a voltage value as output. The voltage value is communicated to a specific MR damper, selected based on the abstract deformed shape of the system, which would ultimately result in improving the response of the system under the effect of earthquake excitation. A sample rule, as defined above, could be written as follows:

$$
\text { IF } \dot{D}_{1}(t) \text { is BIG AND } \ddot{D}_{1}(t) \text { is NEGATIVE SMALL AND P }(t) \text { is } 2 \text { THEN } V_{j}(t) \text { is SMALL (5) }
$$

Where, $\dot{D}_{i}(t)=$ is the velocity at $\mathrm{i}^{\text {th }}$ degree of freedom at a given point in time $(\mathrm{t}), \ddot{D}_{i}(t)=$ is the acceleration of the $i^{\text {th }}$ degree of freedom at a given point in time $(t), P(t)=$ is the abstract deformed pattern at a given point in time $(t), V_{j}(t)=$ is the command voltage to the $j^{\text {th }}$ damper, at a given point in time $(\mathrm{t}), \mathrm{BIG}$, NEGATIVE SMALL and SMALL are fuzzy variables and 2 is a pre-defined abstract pattern, as evaluated by a smart pattern identifier $[17,19,20]$. 


\subsection{Rule-base generation}

The heart of a fuzzy controller is its rule-base. The rule-base houses a collection of IF-THEN rules that summarize the knowledge-base that underpins the decisions made by the fuzzy controller [7, 11]. Being a non-parametric heuristic algorithm, fuzzy controllers are built to simulate a human operator's reasoning when facing a similar control situation. In an effort to design smart sustainable structural systems, that are built to be autonomous systems, the developed rule-base should be capable of handling all potential situations that might arise during the system's expected life time. Such controllers should be designed with self learning capabilities such that their initial rule-bases could be amended and expanded as new experiences and/or situations arise. There are currently several applications and toolboxes that allow the automatic extraction of rules of a given problem, knowing the input/output data sets of the problem without the pre-existing knowledge of a model for the system. This approach might be suitable for ill-defined systems. However, in case of structural systems under earthquake excitation, the system behavior is fully defined and could be identified using finite element models under several types of conventional analysis techniques.

Therefore, it is important to start the creation of the rule-base with a set of rules that outlines the basic features of the problem at hand, if an analytical model of the system could be developed. Such rules could be generated using time history analysis results of finite element models of the structural systems under consideration [14, 15, 16]. The rule-base should be designed to incorporate a self-learning mechanism that is capable of expanding the current rule-base with newly generated rules that capture any new situations [11, 12]. There are several platforms that are designed to allow the creation of fuzzy controllers. The most widely used of these is the MATLAB environment with its fuzzy logic toolbox. This toolbox allows the user the ability to design fuzzy inference systems for control applications or any other applications, such as pattern classification. The toolbox has a user interface that allows the extraction of rules given input/output data sets of the modeled system. As mentioned earlier this approach is suitable for systems that are ill-defined and are difficult to model analytically. The MATLAB environment allows the creation of a static fuzzy inference system. In other words, the created rule base is static and will not expand to incorporate newly acquired experiences. Therefore, it is advisable to create an $\mathrm{m}$-file that is capable of extracting new experiences and expanding the initial rule-base as the need arises. This is usually encountered when the system is faced with a set of input variables that do not fire any of the generated rules [11, 12]. The designer should define a mechanism whereby an initial rule, that defines the encountered case, is generated and then fine tuned later using a performance monitoring scheme [11, 12].

\section{Reliability assessment of fuzzy controllers}

Engineering, by nature, is not an exact science. Engineering systems encounter several sources of uncertainties which render such systems subject to potential failures with certain probabilities. It is rather unrealistic to attempt to design a perfect engineering system with a 
failure probability of zero [21 22, 23]. Yet, it is crucial to be able to evaluate the failure probability of any designed system and attempt to design such systems with predefined and acceptable probabilities of failure [21, 22, 23]. Such acceptable values would be comparable to other failure probabilities humans are accepting and facing in other daily activities [21, 22, 23]. Non-parametric systems are often heuristic in nature and should be carefully analyzed in order to ensure their safe and reliable performance under all expected loading conditions. Smart structural systems, as outlined earlier, comprise sets of integrated components which provide added functionalities to the system, as opposed to conventional structural systems. Despite the fact that some of these components might have been proven reliable, in other applications, their reliable performance as an integral component of such a system needs validation and confirmation $[8,9]$.

In order to develop a comprehensive reliability assessment scheme for smart structural systems, a generic reliability assessment framework needs to be defined. The generic framework functions as a blueprint that identifies the reliability assessment procedures and underlying models, functions and measures that are necessary to perform the reliability assessment as per the nature of the problem at hand $[8,9]$.

Furthermore, it is crucial to develop proper reliability measures and assessment procedures, at two basic levels. First, individual components shall be investigated, given the appropriate failure conditions that are of concern to the application at hand. Second, the overall system, where all underlying components are integrated and aggregated within a predefined limit state format, shall be investigated in order to evaluate an overall reliability of the resulting system. In this chapter, reliability assessment of a fuzzy controller as a component within a smart structural system is explored. The evaluation of an overall reliability of the system, as a whole, is beyond the scope of this chapter and is addressed in other publications $[8,9]$.

\subsection{Reliability assessment framework}

The main objective of this task is to outline a generic reliability assessment framework for evaluating the reliability of a fuzzy controller, as an integral component of a smart structural system. Figure 8 shows the reliability assessment framework for the fuzzy controller, when operating within a smart structural system. The framework identifies two main paths which are necessary to conduct any reliability assessment. The first identifies the main components which are involved in evaluating the commanded output of the controller, while the second identifies another set of components which are responsible for evaluating what would be the expected output of the fuzzy controller. The output of both paths, i.e., commanded output (supply) and expected output (demand), are the basic inputs to any reliability assessment procedure $[9,21,22,23]$.

The reliability assessment framework, when identifying the components involved in each of the referred paths, pinpoints several systems that need to be analytically modeled in order to be able to perform the reliability assessment as necessary. Figure 8 recognizes the following models; a structural model, i.e., finite element model of the system, fuzzy 
controller's model, inverse dynamics model and an inverse actuator's model. All these components need to be defined and their analytical models developed in order to conduct the reliability assessment procedure. It should be pointed out that any system definition needs to be conducted in a format that lends itself to the reliability assessment calculations $[8,9]$. Reliability assessments are related to the failure to supply what is initially demanded from the system. Potential failure modes, the identification of which is one of the first steps in the reliability assessment procedure, define situations where the analyzed system fails to supply and/or provide the required and/or demanded output. These potential failure modes are usually better expressed in a limit state format since this format lends itself to further developments in order to fully conduct the reliability assessment calculations. The following sections outline procedures for creating models for relevant components, identifying potential failure modes, presenting such failure modes in a limit state formats and finally conducting the reliability evaluation of a fuzzy controller.

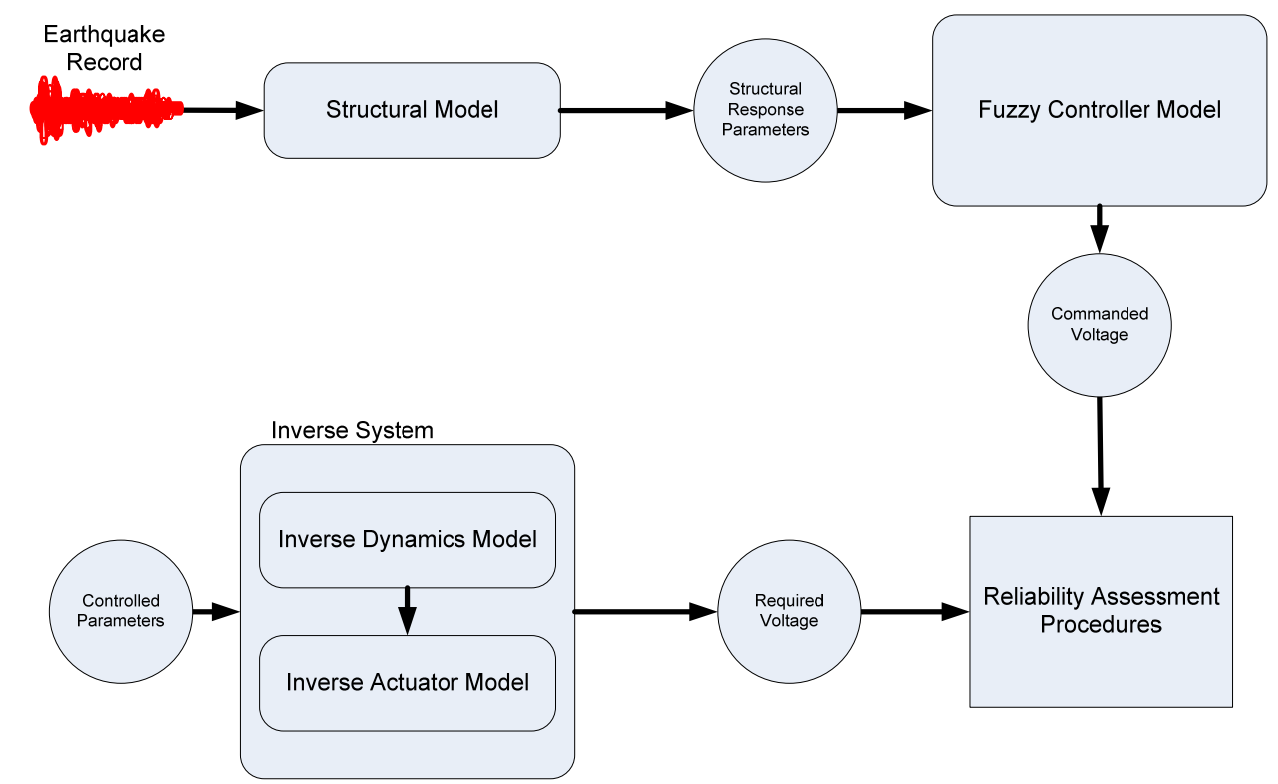

Figure 8. Fuzzy Controller Reliability Assessment Framework

\subsection{Analytical models}

As indicated earlier, the reliability assessment framework outlines the basic components which are involved in the evaluation of the reliability of the modeled system. The framework, shown in Figure 8, identifies four main components that should be analytically modeled in order to perform the reliability assessment procedure. The first component is a finite element model of the structural system which is necessary in order to evaluate the performance parameters of the system under the effect of an earthquake forcing function. Finite element models of structural systems are very well documented and any structural engineer is 
capable of creating such models within one of many finite element software packages that are currently available for research and design purposes. The dynamic equation of motion, shown in Eq. 6 outlines the behavior of a single degree of freedom system under the effect of an earthquake forcing function $[14,15,16]$. Given the time history of the applied earthquake, i.e., $\ddot{x}_{g}(t)$, the solution of the equation shown in Eq. 6 results in the structural performance parameters of the modeled system, i.e., $\ddot{x}(t), \dot{x}(t) \& x(t)[14,15,16]$.

$$
m * \ddot{x}(t)+c * \dot{x}(t)+k * x(t)=-m * \ddot{x}_{g}(t)
$$

Where, $\mathrm{m}=$ floor mass; $\mathrm{c}=$ damping constant; $\mathrm{k}=$ system stiffness; $\ddot{x}(t), \dot{x}(t) \& x(t)=$ are acceleration, velocity and displacement of the floor level, respectively and $\ddot{x}_{g}(t)=$ is the ground acceleration.

The second component is the fuzzy controller model which was discussed in the previous sections. The development of such a model could be performed within a platform that supports fuzzy logic such as MATLAB among others. The development of such a model requires the full definition of input and output variables, including their relevant membership functions, the selection of a suitable inference engine, including inference function, inference mechanism and aggregation function. Finally, this also includes the generation of the rule-base necessary to perform any inference in order to evaluate the output of the controller, given the values of input variables.

The remaining models are relevant to the inverse performance of the system which would start with the controlled structural parameters and back calculate the necessary controller output in order to reach that targeted performance [19, 25]. The inverse system comprise two main components an inverse dynamics model and an inverse actuator model. The inverse dynamics model is simply the dynamic equation of motion which models the behavior of a controlled structural system under the effect of an earthquake loading function. Eq. 6 models the dynamic response of the uncontrolled structural system. Eq. 7, however, includes an additional term that reflects the effect of a control force provided by the fuzzy controller [1, 2]. Eq. 7 should start by introducing a set of required structural parameters, these could be the result of a predefined deformed position which would provide the displacement of the floor level, then by using numerical methods, the accompanying velocity and acceleration could be evaluated and substituted in Eq. 7 to evaluate the required control force.

$$
F_{\text {required }}=m *\left[\ddot{x}(t)+\ddot{x}_{g}(t)\right]+c * \dot{x}(t)+k * x(t)
$$

Where, $\mathrm{m}=$ floor mass; $\mathrm{c}=$ damping constant; $\mathrm{k}=$ system stiffness; $\ddot{x}(t), \dot{x}(t) \& x(t)=$ are acceleration, velocity and displacement of the floor level, respectively and $\ddot{x}_{g}(t)=$ is the ground acceleration and $\mathrm{F}_{\text {required }}=$ required control force. The identification of such predefined deformed shape would be mostly dependent on the nature of the system in question, its size and its level of importance. 
A second inverse model is necessary in order to translate the required control force into a required voltage which is the output of the fuzzy controller. This model should depend on the actuator, which is proposed in the application under consideration. For the proposed system, an MR damper is employed in applying any required corrective actions to enhance the system's response. MR dampers have very well documented models that outline the relationship between the input voltage to the damper and the resulting force, given the damper parameters and response parameters of the controlled system [26, 27]. The modified Buc-Wen model is the most widely used and accepted within the community of smart materials $[26,27]$. The outlined model requires input data relating to the response of the system, i.e., displacement $(\mathrm{x})$ and velocity $(\dot{x})$, in addition to the applied voltage $(\mathrm{v})$, in order to evaluate the MR damper force that would be applied to the system [26, 27, 28].

\subsection{Potential failure modes}

The evaluation of the supplied and demanded fuzzy controller output values is the first step in the reliability assessment calculations. Potential failure modes should be formulated, in order to define situations where the supplied output variable might not satisfy the demanded requirements and thus constitutes a failure condition for the fuzzy controller [9, 19]. The failure modes are formulated in a limit state format in order to lend themselves to the reliability calculations that follow $[9,19]$. In order to demonstrate the development of such failure conditions, two potential failure modes are explored for the proposed fuzzy controller. The first is a CRASH failure where the controller fails to produce any voltage signal, i.e., output value, to the MR Damper. The second is a MALFUNCTION failure where the controller produces an inaccurate voltage signal to the MR Damper. The reasons for each failure condition should be explored and all potential situations should be considered in evaluating a representative estimate of the reliability of the system $[9,19,28]$.

When evaluating failure conditions all potential situations resulting in such a failure shall be considered and included in the probability of failure to reflect the level of uncertainties involved in the problem [21, 22, 23, 28]. The probability of failure of the controller is, then, evaluated using a Monte-Carlo simulation algorithm where the probability of failure for any given simulation cycle is calculated through the definition of a corresponding limit state as follows [19, 21, 22, 23, 28];

$$
L S_{1}=\frac{V_{\text {sup plied }}}{V_{\text {required }}}<\lambda_{1}
$$

Where, $\mathrm{LS}_{1}=$ is the limit state equation for the first failure mode, $\mathrm{V}_{\text {supplied }}=$ is the supplied voltage command, $\mathrm{V}_{\text {required }}=$ is the voltage demand as evaluated by the inverse models and $\lambda_{1}=$ is a cut off limit which defines when the supplied voltage is considered out of range. In case of a CRASH failure there is a single cutoff limit that defines when the controller is considered to have produced an insignificant output. These ranges are problem dependant and should be evaluated based on practical experience and the knowledge of the modeled 
system's behavior. For the purposes of demonstration if a value of 0.3 is assumed, this means that if the fuzzy controller proposed an output which is less than $30 \%$ of the expected value, this controller is considered to have crashed and is not functioning as expected. The reasons for such failure could be due to the lack of relevant rules that handles the set of input values presented to the fuzzy controller. If the rule-base is designed with the ability to expand and learn from experiences, this failure should trigger the creation of additional rules that are capable of handling such a situation [11, 12].

In case of a MALFUNCTION failure, which is defined as an inaccurate controller output, a single limit can't properly define such a failure condition and as a result two limits need to be defined. The limits would define an acceptable range within which the output is expected to fall. If the controller's output is below or above that range, the controller is considered to have malfunctioned [28]. This type of failure is addressed by fine tuning currently existing rules within the rule-base. Therefore, in such a case two limits are necessary in order to fully define the failure condition, i.e., a lower limit and an upper limit. Two underlying failure conditions result and two limit state equations could be written to express this failure as shown in Eqs. 9 [28];

$$
\begin{aligned}
& L S_{21}=\frac{V_{\text {supplied }}}{V_{\text {required }}}<\lambda_{21} \\
& L S_{22}=\frac{V_{\text {supplied }}}{V_{\text {required }}}>\lambda_{22}
\end{aligned}
$$

Where, $\mathrm{LS}_{21}$ and $\mathrm{LS}_{22}=$ are the limit state equations for scenarios $1 \& 2$ of the second failure mode, $\mathrm{V}_{\text {supplied }}=$ is the supplied voltage command, $\mathrm{V}_{\text {required }}=$ is the voltage demand as evaluated by the inverse models and $\lambda_{21}$ and $\lambda_{22}=$ are lower and upper cut off limits respectively. Such limits are functions of the type of problem and relevant failure modes and resulting practical implications [28]. Monte-Carlo simulatin could be employed in generating values for all random variables which are involved in the problem at hand. Thus, each simulation cycle will result in a value for $\mathrm{V}_{\text {supplied }}$ and $\mathrm{V}_{\text {required }}$ and a corresponding evaluation of LSi. The probability of failure for a given limit state, at any given point in time, is then evaluated using the following equation $[9,19,21,22,23]$;

$$
P_{f i}(t)=\frac{N_{\lambda}}{N}
$$

Where, $\mathrm{P}_{\mathrm{fi}}(\mathrm{t})=$ is the probability of failure of the $\mathrm{i}^{\text {th }}$ limit state, at any given point in time, $\mathrm{N}_{\lambda}$ $=$ is the number of simulation cycles where the processor output resulted in a failure condition, depending on the failure condition in reference to Eqs. (8) \& (9), and $N=$ is the total number of simulation cycles.

The overall probability of failure of the whole processor should be evaluated, taking into consideration all potential failure combinations. This is accomplished by applying a union operator to evaluate the probability of failure of a single limit state with several underlying scenarios, as well as, the overall probability of failure considering all potential limit states. 
The probability of failure of both limit states described in Eq. 9 could be evaluated as $[19,21$, $22,23,24,28]$;

$$
\begin{aligned}
& P_{f 21}(t)=\frac{N_{\lambda 21}}{N} \\
& P_{f 22}(t)=\frac{N_{\lambda 22}}{N} \\
& P_{f 2}(t)=P\left\{L S_{21} \cup L S_{22}\right\}=P_{f 21}(t)+P_{f 22}(t)-\left(P_{f 21}(t)^{*} P_{f 22}(t)\right)
\end{aligned}
$$

Where, $\mathrm{P}_{\mathrm{f} 2}(\mathrm{t})=$ is the probability of failure of condition (2), $\mathrm{LS}_{21}$ and $\mathrm{LS}_{22}=$ are underlying limit states as defined in Eq. (11), $P_{\mathrm{f} 21}(\mathrm{t}) \& \mathrm{P}_{\mathrm{f} 22}(\mathrm{t})=$ are the probabilities of failure of underlying limit states (22 and 21), $\mathrm{N}_{\lambda 21}$ and $\mathrm{N}_{\lambda 22}=$ are the number of cycles where the processor output resulted in a failure conditions, i.e., $<\lambda_{21}$ and $>\lambda_{22}$ respectively in reference to Eq. 9 , and $N=$ is the total number of simulation cycles. In order to evaluate the overall probability of failure of the processor, taking into consideration all potential limit states, this could be defined as $[19,21,22,23,24,28]$;

$$
P_{f}(t)=P\left\{L S_{1} \cup L S_{2} \cup \ldots \cup L S_{i}\right\}=P_{f 1}(t)+P_{f 2}(t)+\ldots+P_{f i}(t)-\left(P_{f 1}(t) * P_{f 2}(t) * \ldots * P_{f i}(t)\right)
$$

Where, $\operatorname{Pf}_{\mathrm{f}}(\mathrm{t})=$ is the overall probability of failure of the processor, $\mathrm{LS}_{1}, \mathrm{LS}_{2}$ and $L \mathrm{~S}_{\mathrm{i}}=$ are potential limit states as defined in Eqs. $(8 \& 9), P_{\mathrm{f} 1}(\mathrm{t}), \mathrm{P}_{\mathrm{f} 2}(\mathrm{t})$ and $\mathrm{P}_{\mathrm{fi}}(\mathrm{t})=$ are relevant probabilities of failure of limit states, as defined in Eqs. $(10 \& 11)$. The above calculations are performed at a given point in time $\mathrm{T}_{\mathrm{i}}$, which results in an instantaneous reliability measure $\mathrm{P}_{\mathrm{f}}(\mathrm{t})$ for the fuzzy controller. Figure 9, shows a block diagram for the instantaneous reliability calculation procedure, taking into consideration all potential failure modes.

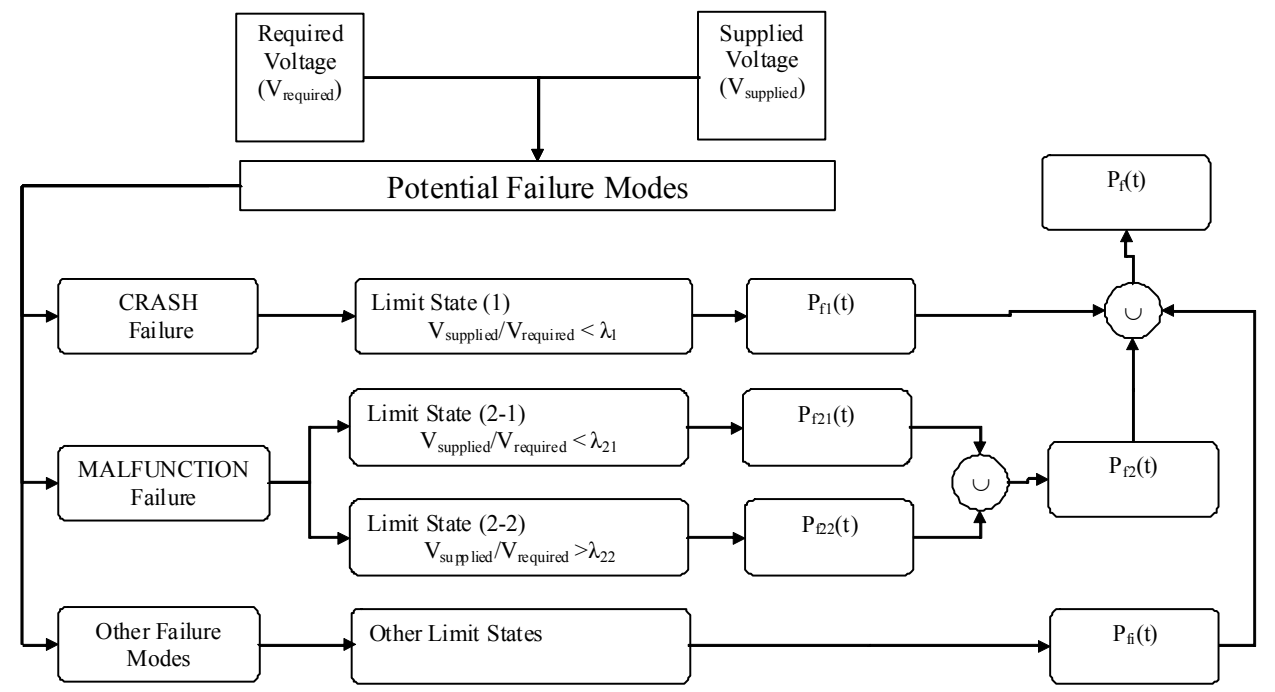

Figure 9. Instantaneous Reliability Evaluation 
The resulting probability of failure is an instantaneous probability due to the time dependant nature of the problem under consideration. Therefore, a reliability time history could be developed to reflect the time variation of the controller reliability during operation under the effect of a real earthquake event. Figure 10, shows the step by step calculation procedure for evaluating a reliability time history for the fuzzy controller. Figure 11, shows a sample reliability time history diagram. The time history diagram is helpful in allowing the user to visualize the performance of the controller during a real time event and thus identifying events where the performance was unacceptable. The indentified time step where the controller failed to satisfy its expected performance could help in pinpointing the reasons for such unreliable behavior.

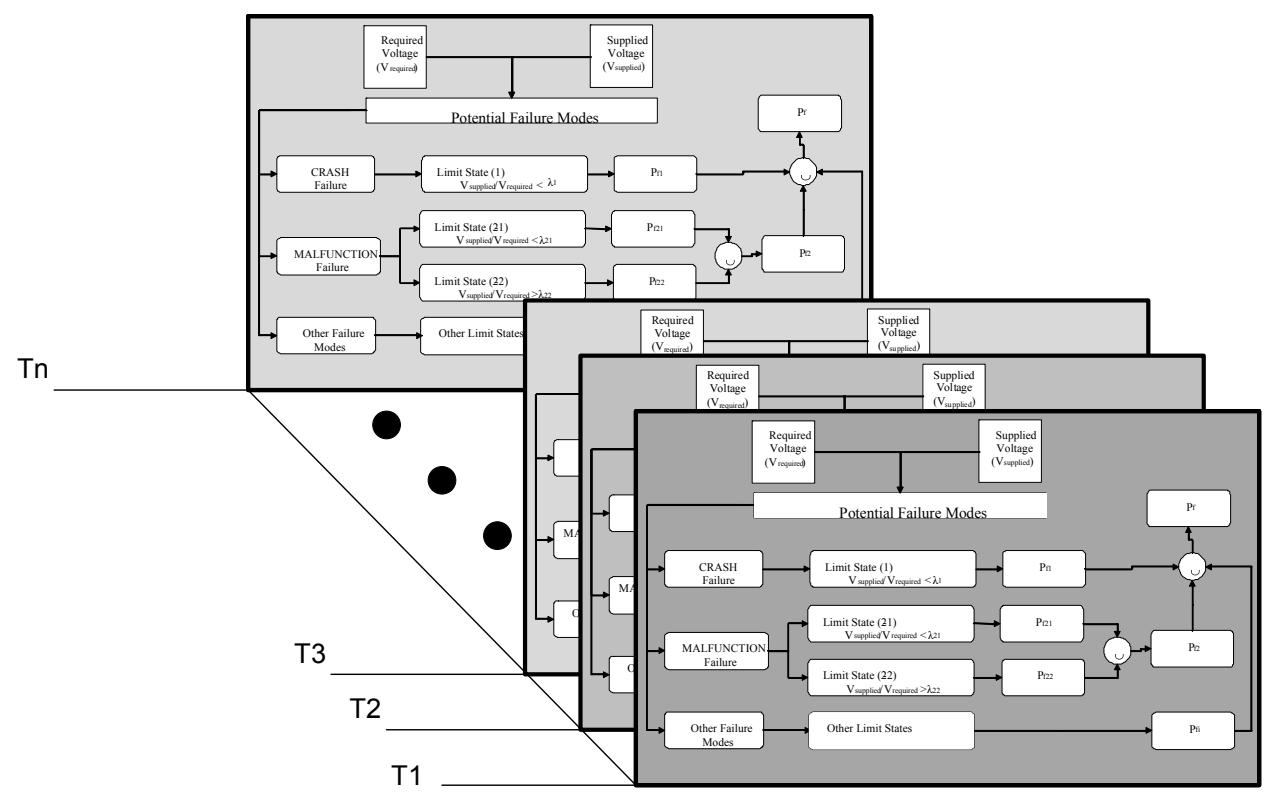

Figure 10. Reliability Time History Evaluation

\section{Enhanced fuzzy controllers}

\subsection{Introduction}

In reference to Figure 2, a multi-degree-of-freedom system would require an enhanced fuzzy controller in order to properly suppress any undesirable response of structural systems under earthquake loadings. One of the important enhancements that could be integrated with the controller is a fuzzy pattern identifier [17, 20, 24]. Sustainable Structural systems, as defined above, are bound by three basic characteristics, i.e., recyclable, optimum and reliable. Optimum design of structural systems entails both the minimum amount of material to construct the system itself, in addition to the optimum use of energy resources and any integral elements that are designed to suppress any undesirable responses. By that 
it is meant the actuators which are integrated within the system. As defined in Figures 1 and 2, these are selected as MR dampers. The designed fuzzy controller should comprise a scheme whereby an optimum firing procedure for such dampers is employed. Such scheme would rely on information relevant to the deformed shape of the system in order to select only those dampers which could significantly affect the response and thus the deformed shape of the system.

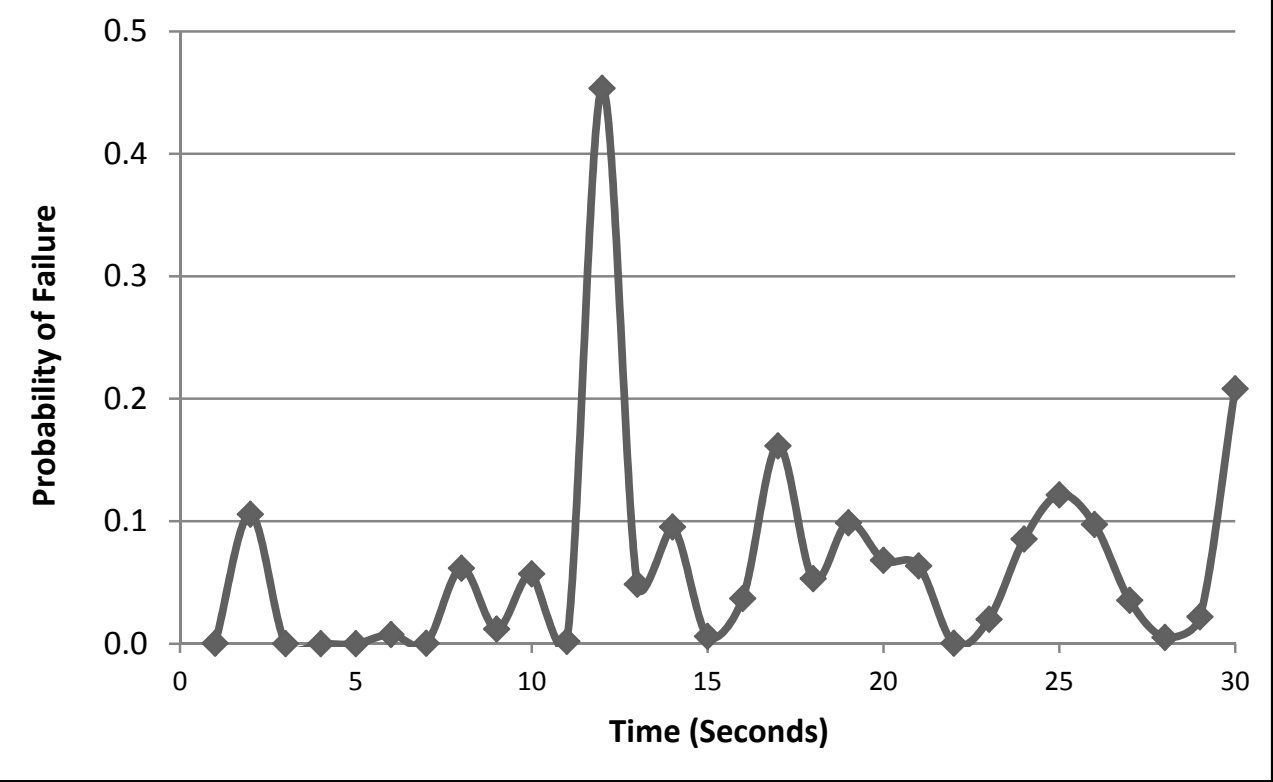

Figure 11. Sample Reliability Time History Diagram

Figure 2 defines an enhanced fuzzy controller where it accepts three input variables instead of only two as discussed earlier. The third variable relates to the abstract deformed shape of the system [17, 20,24]. This additional piece of information would help in the selection of the firing sequence of the MR dampers not just how much restoring force they are called upon to produce. Thus, the need for an additional smart component, to operate integrally with the fuzzy controller, that is capable of classifying the deformed pattern of the system, given the sensor data relevant to the actual position of control points, i.e., degrees of freedom of the system.

A fuzzy inference system, comprising the same basic components of fuzzy controllers, could be designed in order to perform the required pattern classification task [17, 20, 24]. The fuzzy inference system should employ the gathered sensor data in testing the closeness of the deformed shape of the system to predefined abstract deformed patterns that are relevant to the modeled system. An inference engine built on top of a rule-base that is used to assign the 
appropriate pattern classification, based on the displacements of individual degrees of freedom, i.e., displacements of individual floors, could be created to drive the fuzzy inference system. The following section outlines the main design of a fuzzy pattern identifier.

\subsection{Fuzzy abstract deformed shape identifiers}

In order to design a fuzzy inference system that is capable of classifying the deformed pattern of any structural system, a set of potential predefined pattern classifications need to be developed. Such pattern classifications are dependent on the modeled system, its size and its behavior under expected loading conditions. Careful analysis of the modeled system could result in creating such pattern classifications. Figure 12, shows a sample of such potential deformed patterns for a three-degree-of-freedom system. The figure is, by no means, comprehensive, i.e., these are some of the potential deformed patterns a threedegree-of-freedom system could undergo [17, 20, 24].

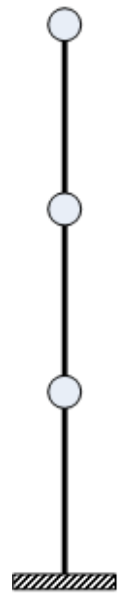

Pattem (0)

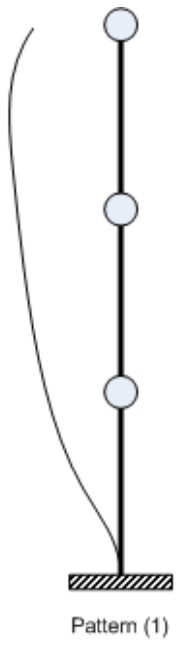

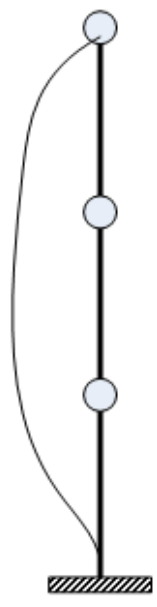

Pattern (1.1)
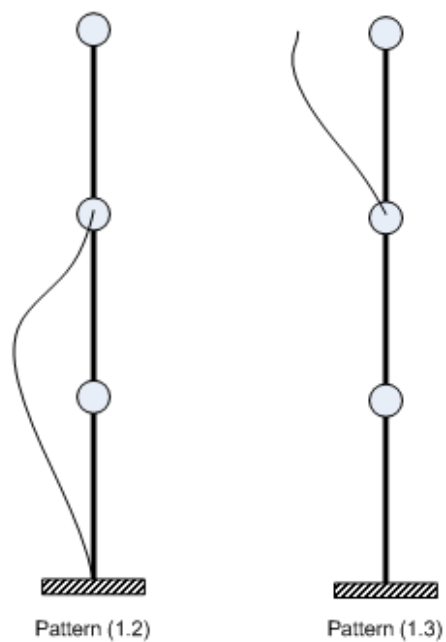

Figure 12. Sample Potential Asbtract Deformed Patterns

Once such pattern classifications are defined, a fuzzy inference system could be designed in order to classify any similar system into one of the predefined patterns. The fuzzy inference system would rely on a relevant rule-base that would accept the input of the individual floor displacements and assign the appropriate pattern classification accordingly. A sample rule could be defined as follows [17, 20, 24]:

$$
\begin{aligned}
& \text { IF (LEVEL1 is Positive) AND (LEVEL2 is Positive) } \\
& \text { AND (LEVEL3 is Positive) THEN (PATTERN is 1) }
\end{aligned}
$$

Where, LEVEL1, LEVEL2 \& LEVEL3 = are fuzzy variables that define the sensor data of relevant story levels, Positive $=$ is a fuzzy value of positive displacement, PATTERN $=$ is the output variable of the fuzzy inference system, $1=$ is a fuzzy singleton that defines the 
assigned pattern, AND = is the logical operator. In order to ensure the generality of the developed inference system, the pattern classifier should employ a normalized value of the sensor data rather than the actual displacement of the control point. The sensor data is normalized with respect to its maximum input value in order to result in input values within the interval $[-1,1]$. In order to classify the abstract shape of a system it is only necessary to identify the relative position of control points with respect to each other rather than their absolute actual position. The normalization function could be defined as follows [17]:

$$
\mathrm{L}_{\mathrm{i}}^{\mathrm{N}}(t)=\frac{\mathrm{L}_{\mathrm{i}}(t)}{\underset{\text { for all } \mathrm{A}}{\operatorname{MAX}}\left(\mathrm{L}_{1}(\mathrm{t}), \mathrm{L}_{2}(\mathrm{t}), \mathrm{L}_{3}(\mathrm{t})\right)}
$$

Where, $\mathrm{L}_{\mathrm{i}}^{\mathrm{N}}(t)=$ is a normalized sensor output at $\mathrm{i}^{\text {th }}$ degree of freedom at a given point in time; $L_{i}(t)=$ is the actual sensor output at $i^{\text {th }}$ degree of freedom at a given point of time; $\mathrm{L}_{1}(\mathrm{t}), \mathrm{L}_{2}(\mathrm{t}), \mathrm{L}_{3}(\mathrm{t})=$ are the three actual sensor outputs at floor levels 1,2 and 3 respectively and $\operatorname{MAX}()=$ is the maximum operator performed over all time instants of a given earthquake record. Therefore, the rule outlined in Eq. 13 should be rewritten to reflect the normalization function as follows;

IF $\mathrm{L}_{1}^{\mathrm{N}}(t)$ is Positive $\operatorname{ANDL}_{2}^{\mathrm{N}}(t)$ is Positive AND $\mathrm{L}_{3}^{\mathrm{N}}(t)$ is Positive THEN PATTERN is $1(15)$

Where, $\mathrm{L}_{1}^{\mathrm{N}}(t), \mathrm{L}_{2}^{\mathrm{N}}(t)$ and $\mathrm{L}_{3}^{\mathrm{N}}(t)=$ are the three normalized sensor outputs which identify the displacement, at each individual story level, at any given point in time; and all other variables are as defined above. The integral structure of the enhanced fuzzy controller results in a dual fuzzy processor where its performance and thus its reliability are dependent on the performance of both components [19]. Referring to Figure 2, it is clear that the fuzzy controller accepts inputs from the fuzzy pattern identifier; therefore, new failure conditions for the dual processor should be developed taking into consideration the possibility of the fuzzy pattern identifier providing inaccurate information to the fuzzy controller and thus causing it to fail [19]. Other failure conditions may arise due to the failure of the pattern identifier to evaluate a pattern, given the data that was provided. All such potential failure conditions should be carefully considered when evaluating the reliability of the dual fuzzy processor [19].

The performance of the fuzzy pattern identifier, as for similar pattern classification algorithms, is usually measured by plotting a linear compliance graph and using its geometrical and statistical information in evaluating the system's performance [17, 20]. Figure 13 shows a sample linear compliance graph. The graph is developed using a plot of the target classifications against the fuzzy pattern identifier classifications then generating a trendline of the plotted data [17]. If the trendline has a zero intercept and has a slope of unity, this implies that the fuzzy pattern identifier has perfectly assigned the proper pattern at all time instances. Therefore, the actual slope of the trendline and how close is the plotted data to that line, both are considered acceptable measures of the performance of the fuzzy pattern identifier and could be used in evaluating its reliability [17]. 


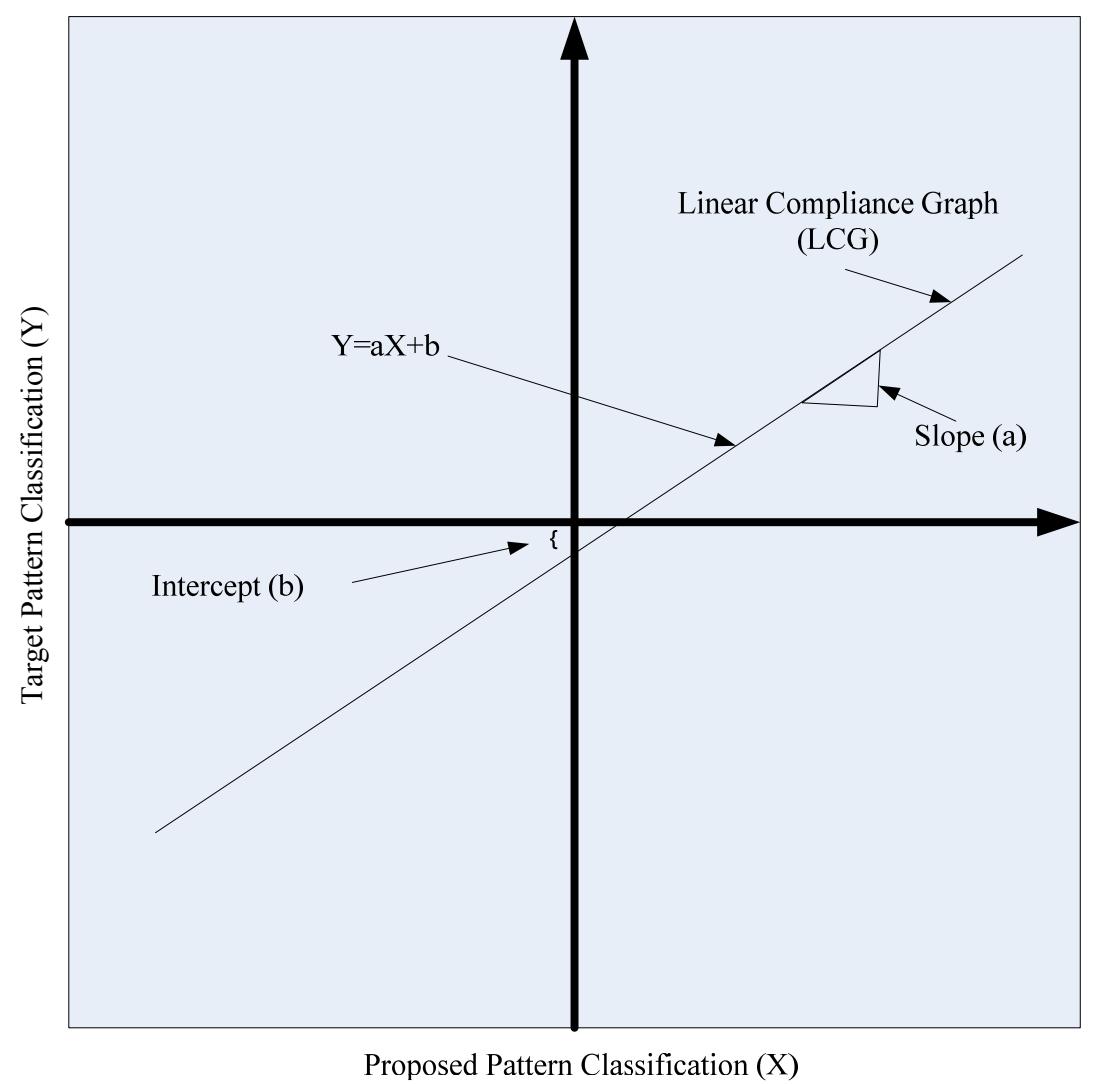

Figure 13. Linear Compliance Graph

\section{Conclusions}

In this chapter sustainable smart structural systems were presented as those which are constructed of recyclable materials, are optimally designed and demonstrate a reliable performance. As such, systems are equipped with fuzzy controllers that allow the structural systems to adjust their response under the effect of highly uncertain loading conditions, i.e., earthquakes. If such loads were considered in the design process it would have resulted in very heavy designs. Moreover, such earthquakes might not even occur during the expected life time of the designed systems. However, if any of these systems is equipped with smart features that adjust its response under the effect of any unseen loading conditions, it would be much lighter, safe and it should be reliable. In addition, the smart characteristics of such systems would minimize, if not eliminate, the amount of damage and destruction and thus the amount of waste, if failures did take place due to the occurrence of unseen earthquake events. 
Smart sustainable structural systems were presented as a simple single-degree-of-freedom system, then, a more complex system was considered. In case of single-degree-of-freedom systems, fuzzy controllers with two input variables and single output variables were discussed. However, in case of more complex systems, the notion of a dual fuzzy processor where a fuzzy pattern identifier feeds additional information to the fuzzy controller was presented. Fuzzy inference systems were discussed in relation to the type of membership functions to be employed in similar applications and the method of generating the necessary rule-bases.

The reliability of such non-parametric systems is of major concern and thus a reliability assessment framework for evaluating the reliability of fuzzy controllers was presented. Potential failure conditions and limit state equations were presented as the basic tool of formulating the reliability problem of a fuzzy controller. The reliability evaluations were performed instantaneously then a reliability time history was created to suit the time dependent nature of the problem at hand.

Finally, the concept of a fuzzy pattern identifier was presented using a fuzzy inference system which would be coupled with the fuzzy controller to form a dual fuzzy processor. Such structure is necessary in case of complex structural systems where the basic information of the dynamics of control points would not be enough to fully define the problem for the controller to formulate proper decisions.

\section{Author details}

Maguid H. M. Hassan

British University in Egypt (BUE), Cairo, Egypt

\section{References}

[1] Soong, T.T. (1990) Active Structural Control, Theory \& Practice. New York: John Wiley \& Sons Inc.

[2] Connor, J.J. (2003) Introduction to Structural Motion Control. New Jersey: Prentice Hall, Pearson Education.

[3] Spencer Jr., B.F. and Sain, M.K. (1998) Controlling Buildings: A New Frontier in Feedback. Control Systems Magazine, IEEE, Special Issue on Engineering Technology, 17, no. No. 6, pp. 19-35.

[4] Spencer Jr., B.F., and Soong, T.T. (1999) New Applications and Development of Active, Semi-Active and Hybrid Control Techniques for the Seismic and Non-Seismic Vibration in the USA. Proceedings of the Inter. Post-SmiRT Conf. on Seismic Isolation, Passive Energy Dissipation and Active Control of Vibration of Structures, Cheju, Korea.

[5] Casciati, F., Faravelli, L. and Yao, T. (1994) Application of fuzzy logic to active structural control. Proceedings of the Second European Conference on Smart Structures and Materials, pp. 206-209. 
[6] Choi, K-M., Cho, S-W., Jung, H-J. and Lee, I-W. (2004) Semi-Active Fuzzy Control for Seismic Response Reduction using Magneto-rheological Dampers. Earthquake Engng. Struct. Dyn., 33, p. 723-736.

[7] Klir, G. J. and Folger T. A. (1988) Fuzzy Sets, Uncertainty, and Information, Prentice Hall, New Jersey.

[8] Hassan, M.H.M. (2006) A System Model for Reliability Assessment of Smart Structural Systems. Structural Engineering \& Mechanics, An International Journal (Techno Press) 23, no. 5, pp. 455 - 468.

[9] Hassan, M.H.M. (2005) Reliability Evaluation of Smart Structural Systems. IMECE2005, ASME International Mechanical Engineering Congress \& Exposition, November 5-11, Orlando, Florida USA.

[10] Hassan, M.H.M, Ayyub, B.M. and Bernold, L. (1991) Fuzzy-based real-time control of construction activities. in Analysis and Management of Uncertainty: Theory and Applications, Edited by Ayyub, Gupta and Kanal, Elsevier, pp. 331-349

[11] Ayyub, B.M. and Hassan, M.H.M. (1992) Control of Construction Activities: III. FuzzyBased Controller. Civil Engineering Systems vol. 9, pp. 275-297.

[12] Hassan, M.H.M. and Ayyub, B.M. (1997) Structural fuzzy control. in Uncertainty Modeling in Vibration, Control and Fuzzy Analysis of Structural Systems, Edited by Ayyub, B.M., Guran, A. and Haldar, A. World Scientific, Chapter 7, pp. 179-231.

[13] Hassan M.H.M. and Ayyub B.M., (1993) A fuzzy controller for construction activities. Fuzzy Sets and Systems, Vol. 5, No. 3, pp. 253-271.

[14] Chopra, A.K. (2007) Dynamics of Structures, Theory and Applications of Earthquake Engineering, Pearson, Prentice Hall, New Jersey.

[15] Paz, M. and Leigh, W. (2004) Structural Dynamics, Theory and Computation, Springer.

[16] Hart, G.C. and Wong, K., (2000) Structural Dynamics for Structural Engineers, John Wiley \& Sons. Inc., New York.

[17] Hassan, M.H.M. (2011) FIS Model of an Abstract Shape Identifier for Structural Systems. In Review.

[18] Ang, A.H-S., and Tang, W.H. (2007) Probability Concepts in Engineering Emphasis on Applications to Civil and Enviroenmental Engineering, John Wiley \& Sons, Inc., New York.

[19] Hassan, M.H.M. (2012) Reliable Smart Structural Control. 5 ${ }^{\text {th }}$ European Conference on Structural Control, EACS 2012, Genoa, Italy, June 18-20.

[20] Hassan, M.H.M. (2012) Real-Time Smart Shape Identifiers. $4^{\text {th }}$ International Conference on Smart Materials, Strutcures \& Systems, CIMTEC 2012, Montecantini Terme, Italy, June 10-14.

[21] Ditlevsen, O. and Madsen, H.O., (1996) Structural Reliability Methods, John Wiley and Sons, New York.

[22] Haldar, A. and Mahadevan, S., (2000) Probability, Reliability and Statistical Methods in Engineering Design, John Wiley \& Sons, INC., New York.

[23] Nowak, A.S., and Collins, K.R. (2000) Reliability of Structures McGraw-Hill, Inc., Boston. 
[24] Hassan, M.H.M. (2010) Toward Reliability-Based Design of Smart Pattern Identifiers for Semi Active Control Applications. Fifth World Conference on Structural Control and Monitoring, 5WCSCM 2010, Tokyo, Japan, July 12-14.

[25] Hassan, M.H.M. (2008) A Reliability Assessment Model for MR Damper Components within a Structural Control Scheme. Advances in Science \& Technology, Vol. 56, pp 218224.

[26] Dyke, S. J., Spencer Jr. B. F., Sain, M. K. and Carlson, J. D. (1996) Modeling and Control of Magneto-Rheological Dampers for Seismic Response Reduction. Smart Mater. Struct., 5, p. 565-575.

[27] Spencer Jr., B.F., Dyke, S. J., Sain, M. K. and Carlson, J. D. (1997) Phenomenological Model for Magneto-rheological Dampers. J. Engrg. Mech. 123 (3), p. 230-238.

[28] Hassan, M.H.M. (2008) A Reliability Assessment Model for MR Damper Components within a Structural Control Scheme. Third International Conference Smart Materials, Structures \& Systems, Acireale, Sicily, Italy, June 8-13. 